\title{
MENINGKATKAN VISIBILITAS DAN MEMPERBAIKI POSISI KERJA SAAT MELAKUKAN PERAWATAN GIGI DENGAN MENGGUNAKAN LUP
}

\author{
I Putu Gede Andyka Yasa ${ }^{12}$ \\ ${ }^{1}$ Bagian Radiologi Kedokteran Gigi, Fakultas Kedokteran Gigi, Universitas Mahasaraswati, Denpasar \\ ${ }^{2}$ Mahasiswa Pasca Sarjana Ilmu Kedokteran Dasar, Bagian Fisiologi, Fakultas Kedokteran, \\ Universitas Udayana, Denpasar \\ E-mail: andykadrg@gmail.com
}

\begin{abstract}
Dental practitioner often have to work in a very limited areas. Small object, narrow field of view, and poor lighting make a dental treatment difficult to perform correctly. Some procedures require a long time to be completed, forcing dental practitioner to work in a static condition and awkward position for quite a long time. Therefore, they are very susceptible to musculoskeletal disorders. Dental loupe represents a magnification which can be used to overcome this problem. It will provide enough visualisation, so we can work with normal working posture. There are various types of dental loupe sold on the market with varying prices range, so that we have a lot of choice of products. This article review was gathered from several scientific database to find out the use of dental loupe and working posture among dental practitioner and showed a moderate evidence that dental loupe improve working posture among dental profession.
\end{abstract}

Keywords: dental loupe, magnification, working posture, dentistry

\section{PENDAHULUAN}

Gangguan musculoskeletal atau musculoskeletal disorder (MSD) dalam beberapa tahun terakhir menjadi sebuah masalah yang sering dijumpai dalam kehidupan sehari-hari. Berbagai macam profesi termasuk dokter gigi, berpeluang terkena gangguan muskuloskeletal. Kelainan ini menjadi salah satu penyebab tenaga professional tidak mampu bekerja dengan baik dan menghambat produktivitas kerja. Waktu dan biaya yang diperlukan untuk melakukan terapi gangguan $M S D$ cukup besar dan lama, sehingga akan berdampak kepada kesehatan finansial pekerja tesebut ${ }^{1-3}$. Dokter gigi merupakan salah satu profesi yang rentan terkena MSD selama masih aktif bekerja. Munculnya gejala nyeri ringan pada puggung dan leher kadang dianggap gejala yang sepele yang bisa diabaikan. Jika gejala ini terjadi secara terus menerus, maka kerusakan kumulatif fisiologis tubuh dapat menyebabkan cedera sistemik dan memaksa untuk pensiun dini dari pekerjaannya. MSD pada dokter gigi telah banyak diteliti di seluruh dunia ${ }^{4}$.

MSD dapat didefinisikan sebagai kelainan pada muskuloskeletal yang disebabkan oleh beban kerja yang dan diperburuk oleh lingkungan kerja yang tidak sehat dalam periode waktu yang lama. Ada beberapa faktor resiko yang dapat memicu terjadinya MSD, misalkan pekerjaan yang memerlukan kekuatan otot yang berulang-ulang, Kontraksi otot lengan dalam waktu lama, mengangkat beban berat, dan posisi yang tidak ergonomis. Intensitas, frekuensi, dan durasi terpapar keadaan tersebut akan akan mempengaruhi tingkat resiko MSD. Beberapa masalah klinis yang umumnya ditemukan pada pasien dengan MSD adalah sakit pada punggung bawah, punggung, tangan dan pergelangan tangan akibat fleksi dan ekstensi yang terus menerus ${ }^{5-8}$. Pekerjaan di bidang kedokteran gigi bukanlah sebuah pekerjaan yang mudah, melainkan suatu prosedur yang sangat kompleks dari menentukan diagnosa hingga mengevaluasi perawatan. Pekerjaan ini membutuhkan interaksi antara pasien dan dokter gigi pada ruang kerja yang terbatas dan berbagai macam karakter pasien. Dokter gigi yang memiliki kesehatan yang baik adalah salah satu faktor yang penting dalam menentukan tingkat kesuksesan suatu perawatan ${ }^{2,9}$.

Dokter gigi akan menghadapi banyak sekali tantangan dalam melakukan praktek sehari-hari. Hal ini disebabkan oleh karena bekerja di dalam rongga mulut yang kecil, lapang pandang yang sempit, akses yang sulit, basah, kurangnya visibilitas yang membuat perawatan menjadi sangat sulit dilakukan. Sehingga berbagai factor-faktor penyulit ini harus dikontrol dari awal sampai akhir perawatan. Beberapa penelitian menyebutkan bahwa dengan melakukan isolasi yang baik pada daerah kerja dengan rubber dam, meningkatkan pencahayaan, menggunakan kursi ergonomis, dan menggunakan lup dapat mengatasi masalah gangguan MSD yang mungkin akan ditimbulkan ${ }^{10}$.

Lup merupakan sebuah alat bantu yang dapat memberikan pembesaran yang cukup saat melakukan perawatan sehingga dapat meningkatkan kualitas perawatan gigi. Lup telah banyak digunakan dalam berbagai macam perawatan gigi seperti dalam bidang konservasi gigi digunakan untuk meningkatkan akurasi dalam mendeteksi karies, membantu preparasi kavitas, sehingga dapat menegakkan diagnosis dan rencana perawtan dengan tepat. Dalam bidang prostodontik, lup dapat meningkatkan visualisasi saat preparasi gigi untuk pembuatan mahkota. Sementara dalam bidang ortodontik lup digunakan untuk mengevaluasi kerusakan mahkota setelah perawatan selesai dilakukan. Dalam bidang endodontik, lup dapat memperlihatkan orifice dengan jelas, sehingga 
mengurangi kemungkinan saluran akar gigi tidak terawat karena tidak terdeteksi. Dalam bidang periodontk lup mampu meningkatkan akurasi saat pengukuran kedalaman poket dengan probe. Pada bidang ilmu interdispliner, seperti kedokteran gigi estetik, lup akan meningkatkan kualitas perawatan estetik secara signifikan ${ }^{11-12}$.

Tuntutan pasien untuk mendapatkan perawatan gigi yang baik memaksa dokter gigi untuk selalu bekerja dengan konsentrasi tinggi dan terkadang dalam waktu yang lama. Untuk itu dokter gigi memerlukan visibilitas yang baik pada daerah kerja. Keterbatasan daerah kerja memakasa dokter gigi untuk melakukan perubahan posisi dari posisi normal. Pergerakan tubuh ini akan menghasilkan posisi tubuh yang tidak normal seperti inklasi badan, torsi leher dan spinal, serta pundak yang membungkuk. Modifikasi dari postur normal ini dapat mengarah pada MSD jangka pendek atau panjang. Untuk meminimalkan kondisi tersebut, maka dokter gigi dianjurkan untuk menggunakan lup secara rutin dalam pekerjaan klinik Bahkan, lup sudah harus mulai diperkenalkan pada mahasiswa kedokteran gigi saat proses pendidikan berlangsung. Akan tetapi, lup juga memiliki beberapa kekurangan yang akan mempengaruhi kesehatan penggunanya seperti kontraksi pada mata. Sehingga harus dilakukan adaptasi terlebih dahulu sebelum menggunakan lup dalam pekerjaan klinik sehari-hari ${ }^{13-15}$.

\section{LUP}

Ada beberapa prinsip kerja optik yang sangat penting untuk diketahui berkaitan dengan pembesaran pada lup seperti yang terlihat pada Gambar 1, yaitu: 1). Lapang pandang, 2) Kedalaman area, 3) Sudut pandang, dan 4) Desain lup ${ }^{16}$.

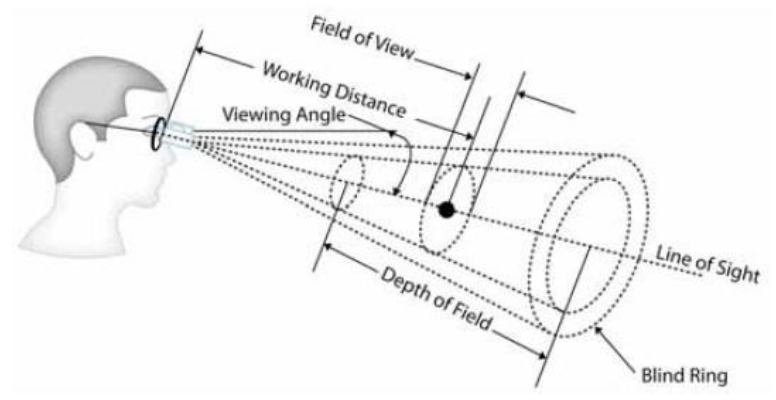

Gambar 1. Optikal terminologi

\section{A. Lapang Pandang}

Lapang pandang sangat berkaitan dengan pembesaran pada lup. Peningkatan pembesaran akan menurunkan lapang pandang. Saat ini di pasaran telah beredar lup dengan berbagai macam pembesaran. Akan tetapi, pembesaran $2 \mathrm{x}-2,5 \mathrm{x}$ sudah cukup untuk melihat beberapa area dalam mulut. Saat pembesaran dinaikkan menjadi 3.5x, maka lapang pandang menjadi lebih sempit sampai hanya meliputi satu kuadran. Jika pembesaran melebihi $3.5 x$, maka lapang pandang menjadi sangat kecil sampai satu gigi. Pembesaran yang tinggi tidak dianjurkan untuk pekerjaan klinik sehari-hari, akan tetapi pembesaran ini sangat berguna jika digunakan saat melakukan perawatan endodontik $^{17}$.

\section{B. Kedalaman Area Visual}

Kedalaman area visual didefinisikan sebagai kemampuan lensa untuk menyesuaikan fokusnya pada objek yang dekat dan jauh tanpa mengubah posisi kerja. Jarak penglihatan normal dari posisi kerja adalah tidak terbatas. Kedalaman area berbanding terbalik dengan pembesaran, sehingga meningkatnya pembesaran maka kedalaman area juga akan menurun ke titik terkecil. Ketika operator berpindah posisi saat menggunakan lup dengan pembesaran yang tinggi, maka hal ini akan menyebabkan mereka kehilangan fokus dan bekerja akan menjadi lebih sulit ${ }^{18}$.

\section{Sudut Pandang}

Sudut ini di definisikan sebagai garis imajiner yang ditentukan dari celah auricular superior ke nasal bridge. Sudut ini berkaitan dengan posisi miring kepala. Peningkatan sudut ini akan meningkatkan kemiringan leher untuk melihat objek yang di amati. Hal ini sangat penting untuk memastikan apakah sudut ini merupakan sudut yang benar bagi pengguna lup untuk meminimalisir ketegangan pada leher, pundak dan punggung ${ }^{19}$.

\section{Desain Lup}

Ada dua sistem optikal yang digunakan pada sebuah lup: Galilean dan Prismatik.

\section{Galilean}

Galilean merupakan lup yang paling sering digunakan di kedokteran gigi. Pembesaran lup ini sudah di atur pada pembesarang paling optimal yaitu kurang dari atau sama dengan 3.5x.. Hal ini disebabkan karena menggunakan oleh karena lensa yang dibatasi oleh spherical aberration. Salah satu kekurangan dari lup ini adalah adanya efek halo dan distorsi pada obyek yang diamati. Akan tetapi, lup ini cenderung lebih ringan dan harganya relative lebih murah. Contoh dari Galilean lup dapat dilihat pada Gambar 2.

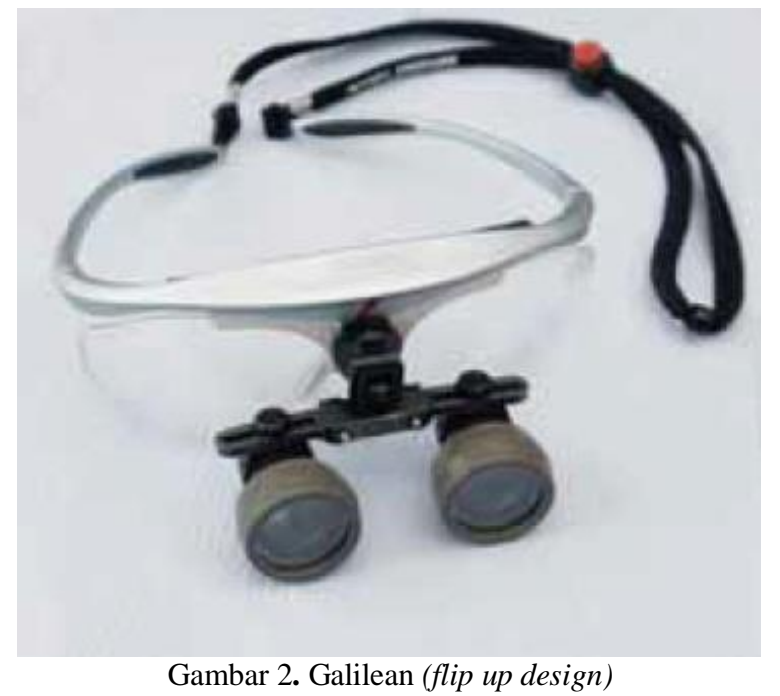

\section{Prismatik}


Prismatik merupakan lup dengan system optikal dengan kualitas paling tinggi yang tersedia saat ini. Sistem prisma memungkinkan cahaya yang lewat diteruskan melalui refleksi, oleh karena itu laras lup akan dibuat cukup pendek untuk kacamata atau ikat kepala. Lup ini lebih baik daripada Galilean dalam hal kualitas pembesaran, lapang pandang dan kedalaman area. Namun, ada beberapa kekurangan dari sistem ini, yaitu lebih berat, laras yang panjang, dan lebih mahal. Lensa pada kedua tipe dapat dipasang pada gagang kacamata, atau tertantam pada lensa kacamata. Lup dengan tipe yang dipasang pada gagang mempunyai kelebihan karena jarak interpupil dapat disesuaikan untuk masing-masing individu. Contoh lup yang menggunakan system prismatic dapat dilihat pada Gambar 3.

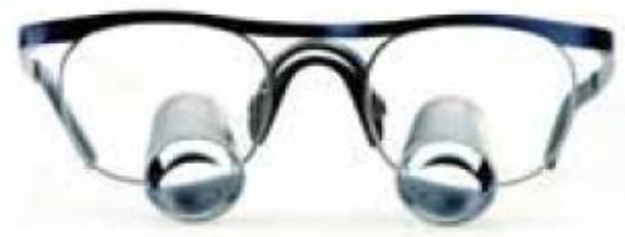

Gambar 3. Prismatik (Through the lens)

\section{LUP DAN PENINGKATAN KEMAMPUAN VISUAL}

Penelitian oleh Gilbert et al yang berkaitan dengan masalah penuaan di kedokteran gigi, menyatakan bahwa dokter gigi seharusnya melakukan pemeriksaan mata setiap 2 tahun sekali sampai usia 50 tahun dan selanjutnya dilakukan setiap setahun sekali. Burton dan Bridgeman dalam penelitiannya mencoba untuk menjelaskan efek usia pada penglihatan dokter gigi pada praktek sehari-hari, sayangnya mereka tidak menemukan data statistik yang signifikan antara ketajaman penglihatan dan jarak kerja. Telah diketahui bahwa jarak kerja akan meningkat dengan adanya penuaan dan dengan bantuan lup maka jarak kerja dapat dijaga dengan nyaman secara konstan, memastikan postur dokter yang tegak $\mathrm{k}^{22-23}$.

Penggunaan lup menjadi semakin populer saat ini, karena adanya tuntutan pasien untuk mendapatkan hasil perawatan yang lebih baik. Beberapa penelitian telah dilakukan untuk menjelaskan apakah lup dapat meningkatkan ketepatan dalam melakukan diagnosis ${ }^{24-}$ ${ }^{26}$. Akan tetapi, karena jumlah sampel yang sedikit maka perlu dilakukan penelitian yang lebih lanjut. Satu penelitian menyatakan bahwa lokasi dan arah fraktur pada gigi dapat dilihat dengan jelas saat menggunakan lup dan pencahayaan yang baik ${ }^{27}$. Pada penelitian yang lain menunjukkan bahwa penggunaan lup akan meningkatkan akurasi diagnosa karies secara in vitro. Whitehead dan Wilson menemukan bahwa performa dokter ketika menggunakan pembesaran akan meningkat secara signifikan ${ }^{24,25}$. Namun sebaliknya, Donaldson dkk tidak dapat menemukan peningkatan yang signifikan pada penelitian yang dilakukan pada mahasiswa kedokteran gigi yang menggunakan lup saat melakukan perawatan konservasi gigi ${ }^{28}$. Penelitian lainnya juga menyatakan bahwa saat melakukan preprasi gigi untuk pembuatan mahkota, pengguna lup mendapatkan banyak manfaat ${ }^{29}$. Selanjutnya, Lussi dkk dalam penelitian mereka mengungkapkan bahwa dengan menggunakan lup pada saat preparasi kavitas di proksimal box dapat menurukan kerusakan iatrogenik pada permukaan gigi yang bersebelahan ${ }^{30}$.

Gultz dkk menjelaskan bahwa ketajaman visual akan meningkat secara signifikan, dalam penelitian kohort yang dilakukan pada mahasiswa dan staff fakultas dengan berbagai usia, meskipun menggunakan lup dengan pembesaran yang rendah ${ }^{31}$. Pada penelitian selanjutnya mereka mengivestigasi perbedaan ketajaman visual ketika menggunakan lup yang menggunakan pencahayaan dengan dan tanpa fiber optik. Penelitian itu dilakukan pada 70 mahasiswa kedokteran gigi dan diperoleh hasil berupa peningkatan ketajaman visual yang signifikan $(\mathrm{P}<0.001$, ANOVA) ketika menggunakan lup yang ditambah dengan sumber cahaya fiber optik. Intensitas cahaya diatas 30.000 lux dianggap aman juga meminimalisir silau. LED yang lebih terang juga tersedia, akan tetapi LED ini menghasilkan silau yang lebih banyak, karena sinar yang direfleksikan dari permukaan gigi, dan mungkin saja tidak aman untuk digunakan dalam jangka waktu yang lama $a^{32}$.

\section{LUP DAN PERBAIKAN POSISI KERJA}

Penggunaan lup pada praktek dokter gigi semakin popular belakngan ini, sehingga banyak dilakukan penelitian untuk menjelaskan hubungan antara penggunaan lup dan postur kerja untuk mengurangi kemungkinan mengalami MSD. Rangkuman hasil kajian pustaka dari beberapa tulisan dapat dilihat pada Tabel 1. Semua penelitian menggunakan berbagai macam tipe lup tapi dengan pembesaran yang sama yaitu $2.5 \mathrm{x}$. Pembesaran ini telah diketahui dapat memberikan lapang pandang yang paling luas, dan fokus yang lebih baik. Jika pembesaran ditingkatkan maka lapang pandang menjadi lebih sempit ke satu kuadran, dan jika terus ditingkatkan, maka lapang pandang menjadi sangat terbatas pada satu gigi. Branson et al menggunakan the see through type, sedangkan yang lain menggunakan desain flip-up. Tiga penelitian lainnya menggunakan metode random sampling untuk menentukan subyek penelitian. Desain penelitian ini membagi kelompok sampel menjadi kelompok perlakuan dan kelompok kontrol. Tiga penelitian lainnya menggunakan desain pretest dan postest. Jumlah sampel yang digunakan bervariasi mulai dari 20 hingga 40 subyek $^{14,15,33}$.

Pada penelitian Branson et al, subyek diminta untuk melakukan pemeriksaan klinis dan seluruh prosesnya direkam dengan kamera. Postur tubuh yang terlihat dinilai dengan menggunakan skor postural assessment index (PAI). Nilai PAI untuk mahasiswa yang menggunakan lup secara signifikan lebih baik $(\mathrm{p}=0.19)$ jika dibandingkan dengan nilai PAI tanpa lup. Nilai rata-rata mahasiswa yang menggunakan lup adalah 12.05 dibandingkan dengan tanpa lup 15.02. Nilai PAI yang rendah menyatakan posisi kerja yang lebih baik $^{14}$. JP Mailet et al mencoba untuk memodifikasi skor PAI dengan mengajukan PAC. 
Terdapat dua perubahan penting dari PAI ke PAC yang mengamati gerakan pergelangan tangan dan lengan atas. Selama observasi mahasiswa diperintahkan untuk melakukan permeriksaan klinis dan direkam dengan kamera video. Hasilnya juga menunjukkan kesesuaian dengan penelitian sebelumnya. Mahasiswa yang menggunakan lup mempunyai postur kerja yang lebih baik dibandingkan dengan tanpa menggunakan lup. Mereka juga menjelaskan bahwa jika semua mahasiswa diperkenalkan dengan lup langsung saat memasuki program, maka pada akhir sesi pertama nilai rata-rata postur mereka akan meningkkat sebesar 2.7 hingga $7.5^{15}$.

Penelitian yang lebih menyeluruh dilakukan oleh M Carpentier et al, dimana dilakukan pengamatan pada berbagai bagian tubuh yang mungkin akan terkena dampak oleh kesalahan postur kerja dan sampel yang digunakan juga lebih banyak. Hasil dari t-test tidak berpasangan menunjukkan skor $P A I$ yang lebih tinggi ketika mahasiswa tidak menggunakan lup (146.3 \pm 6.64 poin/menit) daripada dengan lup (123.2 $\pm 6.77 \mathrm{poin} / \mathrm{menit})$ (t $(70)=2.432, \mathrm{p}=0.0176)$. Namun, tidak ada perubahan statistik yang signifikan pada bagian dada, kepala dan leher, serta lengan atas. Mereka juga meneliti hubungan antara lup saat melakukan preparasi gigi. Kedua kelompok dibandingkan dengan menggunakan uji t-test. Hasil yang diperoleh menyatakan bahwa tidak ada perbedaan yang signifikan antara kedua grup terkait dengan kualitas preparasi untuk kavitas di mesial menurut GV black Class II pada molar pertama dengan atau tanpa lup. Survey tentang penggunaan lup pada penelitian ini juga menyatakan bahwa mayoritas mahasiswa meyakini penggunaan lup dapat memperbaiki postur mereka (100\%), meningkatkan ketajaman penglihatan (95\%), desain yang cukup baik (95\%), waktu beradaptasi yang tidak terlalu lama $(90 \%)$. Selama waktu adaptasi, gejala yang sering muncul adalah vertigo $(43 \%)$ dan sakit mata $(38 \%)^{34}$.

Dua penelitian yang lain yang dilakukan oleh Hayes dkk mengadopsi desain pre-test post-test control group design. Penelitian ini mengamati gejala kelainan muskuloskeletal pada perawat gigi dan mahasiswa klinik yang memakai lup dengan yang tidak memakai lup pada saat melakukan pembersihan karang gigi. Untuk menilai gejala kelainan musculoskeletal digunakan metode DASH (disabilities of the arms, shoulders, and hands) untuk mengamati gejala pada lengan, pundak, dan tangan. Skor NPDS (neck and pain disability scale) digunakan untuk menilai gejala pada leher. Pengamatan dilakukan sebelum menggunakan lup dan setelah menggunakan lup selama 6 bulan. Dalam kelompok perlakuan, terjadi penurunan skor DASH karena menurunnya gejala MSD yang dilaporkan, sementara pada kelompok control diperoleh peningkatan nilai DASH. Secara statistic perbedaan nilai rata-rata DASH antara kelompok perlakuan dan control didapat kan penurunan yang signifikan pada kelompok perlakuan yang menggunakan lup. Akan tetapi, tidak ditemukan perbedaan yang signifikan pada nilai NPDS baik pada kelompok perlakuan maupun kelompok control. Hal ini

menunjukkan bahwa, penggunaan lup tidak mengurangi gejala sakit pada pundak dan leher selama penelitian dilakukan. Penelitian ini juga memeriksa kesehatn fisik pada subyek penelitian oleh fisioterapis. Hasilnya diperoleh bahwa terjadi perbaikan dari waktu ke waktu pada pengguna lup untuk cervical range of motion dan ketahanan otot leher.

Penelitian lainnya memperlihatkan hasil yang sedikit berbeda. Pada penelitian oleh E.A Ludwig et al, mengamati perubahan pada pergerakan tubuh dengan menggunakan accelerometer. Perbedaan hasil yang didapatkan pada penelitian ini mungkin berkaitan dengan metode yang dilakukan. Metode ini merupakan yang pertama dan mungkin tidak terkalibrasi dengan baik untuk menilai perubahan postur tubuh. Oleh karena itu, hasil menunjukkan tidak signifikan secara statistik pada mahasiswa yang menggunakan lup dan tidak. Penelitian lebih lanjut diperlukan untuk menjelaskan apakah metode ini cocok untuk menilai perubahan postur tubuh atau tidak.

Tabel 1. Rangkuman Kajian Pustaka

\begin{tabular}{|c|c|c|}
\hline PENULIS & $\begin{array}{l}\text { METODE } \\
\text { PENELITIAN }\end{array}$ & HASIL \\
\hline $\begin{array}{l}\text { B.G. Branson } \\
\text { et al, } 2004\end{array}$ & $\begin{array}{l}\text { Randomized cross- } \\
\text { over design }\end{array}$ & 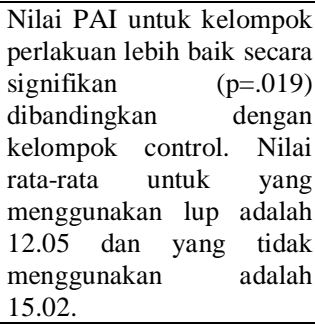 \\
\hline $\begin{array}{l}\text { MJ Hayes et } \\
\text { al, } 2014\end{array}$ & $\begin{array}{l}\text { Pre test post test } \\
\text { control group } \\
\text { design }\end{array}$ & $\begin{array}{l}\text { Perbedaan rata-rata antara } \\
\text { kelompok perlakuan dan } \\
\text { control adalah }(3.39) \text { dan } \\
(-1.59 ; \mathrm{P}=.037) . \text { Terjadi } \\
\text { perbaikan nilai DASH } \\
\text { pada kelompok perlakuan. }\end{array}$ \\
\hline $\begin{array}{l}\text { MJ Hayes et } \\
\text { al, } 2016\end{array}$ & $\begin{array}{l}\text { Pre test post test } \\
\text { control group } \\
\text { design }\end{array}$ & \begin{tabular}{lcr} 
Penggunaan & lup tidak \\
terjadi & \multicolumn{2}{c}{ perubahan } \\
signifikan & pada nilai \\
NPDS. & & \\
\end{tabular} \\
\hline $\begin{array}{l}\text { Maillet et al, } \\
2008\end{array}$ & $\begin{array}{l}\text { Randomized cross- } \\
\text { over design }\end{array}$ & $\begin{array}{l}\text { Terjadi perbaikan postur } \\
\text { secara signifikan pada } \\
\text { kelompok } \\
\text { menggunakan lup dengan } \\
\text { perbedaan rata-rata skor } \\
\text { PAI adalah } 4.4(\mathrm{P}<.001) \text {. }\end{array}$ \\
\hline $\begin{array}{l}\text { M Carpentier } \\
\text { et al, } 2017\end{array}$ & $\begin{array}{l}\text { Randomized cross- } \\
\text { over design }\end{array}$ & 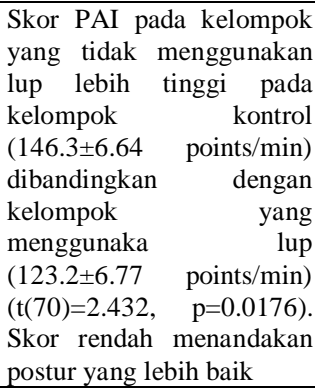 \\
\hline $\begin{array}{l}\text { E A } \text { Ludwig, } \\
2019\end{array}$ & $\begin{array}{l}\text { Pre test post test } \\
\text { control group } \\
\text { design }\end{array}$ & 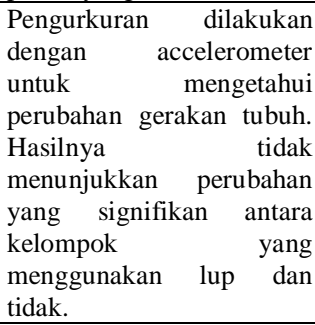 \\
\hline
\end{tabular}




\section{DISKUSI}

Penggunaan lup dalam kedokteran gigi dapat memperbaiki posisi kerja dan mengurangi berbagai gejala yang muncul sebagai tanda MSD. Lup juga dapat meningkatkan kualitas perawatan gigi yang mungkin menjadi salah satu alasan kenapa dokter gigi memilih alat ini sebagai armamentarium tambahan dalam praktek sehari-hari. Akan tetapi, efek menggunakan lup terhadap postur kerja dan sakit muskuloskeletal belum diteliti lebih lanjut ${ }^{16}$. Penggunaan lup oleh mahasiswa kedokteran gigi saat melakukan simulasi perawatan gigi menunjukkan adanya penurunan kesalahan yang dilakukan sampai $50 \%{ }^{29}$, meningkatkan kualitas dari preparasi kavitas ${ }^{37}$, meningkatkan efisiensi dan kecepatan kerja ${ }^{38}$. Penggunaan lup juga meningkatkan akurasi saat mendeteksi karies ${ }^{24}$. Namun, pembesaran melebihi 4.5x mungkin menyebabkan perubahan persepsi sehingga kemungkinan melakukan perawatan berlebihan yang tidak diperlukan ${ }^{65}$. Sementara itu, dalam hal pencegahan kerusakan iatrogenic pada gigi akibat preparasi gigi, penggunaan lup tidak memiliki dampak secara signifikan ${ }^{26,30}$. Penggunaan lup sangat dianjurkan saat melakukan perawatan endodontic. Lup dengan pembesaran $2.5 \mathrm{x}$ dapat meningkatkan kemampuan motorik halus yang diperlukan saat melakukan perawtan endodontik ${ }^{39}$. Demikian pula, dalam sebuah penelitian klinis in vivo, penggunaan lup dapat meningkatkan jumlah saluran akar MB2 dapa gigimolar rahang atas dibandingkan dengan tidak menggunakan lup. Frekuensi deteksi kanal MB2 pada grup dengan mikroskop, lup dan tanpa pembesaran adalah $71 \%, 62.5 \%$, dan $17,2 \%$ secara berurutan. Tidak ada perbedaan yang signifikan yang ditemukan antara penggunaan mikroskop dan lup ${ }^{42}$.

\section{SIMPULAN}

Kebanyakan penelitian menyatakan bahwa lup secara ilmiah meningkatkan postur kerja di kedokteran gigi. Jika lup diperkenalkan sejak dini di pendidikan kedokteran gigi, hal ini akan memberikan keuntungan yang besar bagi kesehatan dokter gigi. Agar dapat menggunakan lup secara benar, dokter gigi perlu melakukan penyesuaian untuk menghindari efek negatif dari lup.

\section{UCAPAN TERIMA KASIH}

Terima kasih sebesar-besarnya saya ucapkan kepada semua pihak yang telah membantu pembuatan tulisan ini. Sehingga tulisan ini dapat dikerjakan dengan baik dan semoga bermanfaat untuk kepentingan semua orang

\section{DAFTAR PUSTAKA}

1. Leggat PA, Kedjarune U, Smith DR. Occupational health problems in modern dentistry: a review. Ind Health. 2007;45:611-621.

2. Mehta S, Mehta A, Lodha S. Occupational hazards in dentistry. Guident. 2014;7:76-78.

3. Ayers KM, Thomson WM, Newton JT, Morgaine KC, Rich AM. Self-reported occupational health of general dental practitioners. Occup Med. 2009;59:142-148.

4. Evangelos C.A., Ioanna-Christina S., Fotini C. Prevalence of musculoskeletal disorders in dentists, BMC Musculoskeletal Disorders 2004, 5:16

5. Finsen L, Christensen $\mathrm{H}$, Bakke $\mathrm{M}$. Musculoskeletal disorders among dentists and variation in dental work. Appl Ergon 1998; 29: 119-125.

6. Lake J. Musculoskeletal dysfunction associated with the practice of dentistry - proposed mechanisms and management: literature review. Univ Tor Dent J 1995; 9: 7-11.

7. Lindfors $\mathrm{P}$, von Thiele U, Lundberg U. Work characteristics and upper extremity disorders in female dental health workers. J Occup Health 2006; 48: 192-197.

8. Puriene A, Janulyte V, Musteikyte M, Bendinskaite R. General health of dentists. Literature review. Stomatologija, Balt Dent MaxillofacJ 2007; 9: 10-20.

9. Hayes MJ, Taylor JA, Smith DR. Predictors of work-related musculoskeletal disorders among dental hygienists. Int J Dent Hyg 2012; 10: 265269.

10. Dong H, Loomer P, Barr A, Laroche C, Young E, Rempel D. The effect of tool handle shape on hand muscle load and pinch force in a simulated dental scaling task. Appl Ergon 2007; 38: 525531.

11. Dong H, Barr A, Loomer P, Laroche C, Young E, Rempel D. The effects of periodontal instrument handle design on hand muscle load and pinch force. J Am Dent Assoc 2006; 137: 1123-1130. 178 | Int J Dent Hygiene 12, 2014; 174-179

12. Piligian G, Herbert R, Hearns M, Dropkin J, Landsbergis P, Cherniak M. Evaluation and management of chronic work-related musculoskeletal disorders of the distal upper extremity. Am J Ind Med 2000; 37: 75-93.

13. Simmer-beck M, Bray KK, Branson BG, Glaros A, Weeks J. Comparison of muscle activity associated with structural differences indental hygiene mirrors. J Dent Hyg 2006; 80: 8.

14. Branson BG, Bray KK, Gadbury-Amyot C et al. Effect of magnification lenses on student operator posture. J Dent Educ 2004; 68: 384-389.

15. Maillet JP, Millar AM, Burke JM, Maillet MA, Maillet WA, Neish NR. Effect of magnification loupes on dental hygiene student posture. J Dent Educ 2008; 72: 33-44

16. James T, Gilmour AS., Magnifying Loupes In Modern Dental Practice: An Update, Dental Update, 2010, Available at: https://www.researchgate.net/publication/497039 00; 633-636

17. Shanelec D. Optical principles of loupes. Calif Dent Assoc 1992; 20(11): 25-32.

18. Powell-Cullingford. Magnificent magnification. BDA News 2007; 20(2): 10-11. 
19. Rucker L, Beattie C, McGregor C et al. Declination angle and its role in selecting surgical telescopes. J Am Dent Assoc 1999; 130: 10961100.

20. Strassler H. Magnification systems improve quality and posture. Insights and innovations. $J$ Esthet Dent 1990; Nov-Dec 2(6): 183-184.

21. Baker JM, Meals RA. A practical guide to surgical loupes. J Hand Surg 1997; 22A: 967974.

22. Burton JF, Bridgman GF. Presbyopia and the dentist: the effect of age on clinical vision. Int Dent J 1990; 40: 303-312.

23. Gilbert J. The dentist and the aging eye. $J M i$ Dent Assoc 1980; May-June 60(3): 22-24.

24. Forgie HP, Pine CM, Pitts N. The use of magnification in a preventive approach to caries detection. Quintessence Int 2002; 33:13-16. Whitehead SA, Wilson NHF. Restorative decision-making behaviour with magnification. Quintessence Int 1992; 23(10): 667-671.

25. Whitehead SA, Wilson NHF. Restorative decision-making behaviour with magnification. Quintessence Int 1992; 23(10): 667-671.

26. Forgie AH. The effect of magnification of clinical caries diagnosis. J Dent Res 1997; 76: 5.

27. Thomas G. The diagnosis and treatment of the cracked tooth syndrome. Aust Prosthodont $J$ 1989; 3: 63-67.

28. Donaldson M, Knight GW, Guenzel PJ.The effect of magnification on student performance in pediatric operative dentistry. J Dent Educ 1998; 62(11): 905-910.

29. Leknius C, Geissberger M. The effect of magnification on the performance of fixed prosthodontic procedures. Calif Dent Assoc $J$ 1995; 23: 66-69.

30. Lussi A, Kronenberg O, Megert B. The effect of magnification on the iatrogenic damage to adjacent tooth surfaces during Class II preparation. J Dent 2003; 31: 291-296.

31. Gultz JSL, Settembrini L, James K, Scherer W. Can you see it? A visual acuity study. J Dent Educ 1996; 60(2): 222.
32. Gultz JSL, Kaim J et al. Using a fibre-optic light to improve visual acuity. J Dent Educ 1997; 61:213.

33. Hayes MJ, Osmotherly PG, Taylor JA, Smith DR, Ho A. The effect of loupes on neck pain and disability among dental hygienists. Work. 2016;53:755-762.

34. Carpentier M., et al, The Effect of Magnification Loupes on Spontaneous Posture Change of Dental Students During Preclinical Restorative Training, Journal of Dental Education, 2019, 83 (4), 407 415

35. Hayes MJ, Osmotherly PG, Taylor JA, Smith DR, Ho A. The effect of loupes on neck pain and disability among dental hygienists. Work. 2016;53:755-762

36. Ludwig E A, The Effect of Magnification Loupes on Dental Hygienists' Posture while Exploring, The Journal of Dental Hygiene, 2017, 91(4), 4652

37. Narula K, Kundabala M, Shetty N, Shenoy R. Evaluation of tooth preparations for Class II cavities using magnification loupes among dental interns and final year BDS students in preclinical laboratory. J Conserv Dent. 2015;18:284-287.

38. Maggio MP, Villegas H, Blatz MB. The effect of magnification loupes on the performance of preclinical dental students. Quintessence Int. 2011;42:45-55.

39. Bowers DJ, Glickman GN, Solomon ES, He J. Magnification's effect on endodontic fine motor skills. J Endod. 2010;36:1135-1138.

40. Buhrley LJ, Barrows MJ, BeGole EA, Wenckus CS. Effect of magnification on locating the MB2 canal in maxillary molars. J Endod. 2002;28:324327.

41. Del Fabbro M, Taschieri S. Endodontic therapy using magnification devices: a systematic review. J Dent. 2010;38:269-275.

42. Del Fabbro M, Taschieri S, Lodi G, Banfi G, Weinstein RL. Magnification devices for endodontic therapy. Cochrane Database Syst Rev 2015: Cd005969. 